\title{
F-5 - Academic Reinforcement Project of Biochemistry I Discipline of UFRGS Pharmacy Course
}

Vera Maria Treis Trindade ${ }^{1}$, Carolini da Silva ${ }^{1}$, Vinícius Vernier Nunes ${ }^{1}$, Bruna Teixeira Coelho ${ }^{1}$, Pedro Henrique Olmedo de Freitas ${ }^{1}$, Christianne Gazzana Salbego ${ }^{1}$

${ }^{1}$ Universidade Federal do Rio Grande do Sul, Bioquímica (RS, Brasil)

\begin{abstract}
INTRODUCTION: Biochemistry studies chemical transformations in uni or multicellular living beings. It analyzes physiological processes and evaluates their modifications in pathological conditions. It assists in diagnosis and pharmacological intervention of several diseases, characterizing its importance in health area. In Pharmacy graduation course (UFRGS) until 2017 there were two disciplines - Biochemistry I and Biochemistry II - offered by the Biochemistry Department, ICBS. Both were compulsory, present in third and fourth curriculum stages, had eight credits, distributed in theoretical, theoretical-practical and practical contents. OBJECTIVES: The purpose of this work was to report the development, since the second half of 2014 year, of this project which offered extra class assistance to students with difficulty to understand the Biochemistry I contents. MATERIALS AND METHODS: The project was developed weekly by student-monitor, according to the demand of registered students. The reviewed contents were: amino acids, peptides, proteins, enzymes, biological oxidation, chemistry and carbohydrate metabolism. The activities were previously commented by the participating teachers and monitor. The classroom or distance methodologies consisted of: a) discussion of thematic doubts between students and the monitor; b) resolution of pertinent exercises; c) navigation guided in learning objects. DISCUSSION AND RESULTS: One of the goals of the reinforcement project was to reduce the failure rate of students enrolled in the discipline to $25 \%$. We observed that this objective was surpassed in the semester 2015-1, where the percentage of disapproval fell to 8.5\%. But in 2015-2 this percentage rose to $31 \%$. However, it is worth mentioning the massive approval of the participating students during the six semesters in which the project was developed (70-85\%). CONCLUSION: These data reveal the project efficiency and the participants' commitment. We intend to continue the reinforcement activities, as an additional tool, for the appropriation of basic Biochemistry knowledge by the future pharmaceutical professional.
\end{abstract}

Keywords: basic biochemistry; monitor; teaching. 